\title{
The Research of the Smart Growth Based on the Gray Prediction Analysis
}

\author{
Chuxuan Zhang \\ School of Environmental Science and Engineering,North China Electric Power University, \\ Baoding 071003, China \\ 527469028@qq.com
}

\begin{abstract}
For a city, the most important thing is not architecture, but planning." Ieoh Ming Pei, a famous Chinese architect, once said. City planning is a comprehensive development tasks and objectives within a certain period. In this paper, we first select 20 indicators ,which conform to the ten principles and the three E' s of the city smart growth.Secondly, we take the example of Darwin, Oceania, to collect data on 20 indicators of smart growth to get the corresponding values,including Economic Index(EI), Social Equal Index(SEI), Environmental Sustainability Index(ESI) and Smart Growth Index(SGI).Then, through the gray prediction model, we can get the changing trend and value of the related index.Finally, through the changing tendency, we will alter unreasonable index by implementing effective measures to achieve smart growth.
\end{abstract}

Keywords: smart growth;gray prediction;evaluation metric.

\section{Introduction}

"Smart growth is about helping every town and city become a more economically prosperous, socially equitable, and environmentally sustainable place to live." [1] "The ten principles for smart growth are ${ }^{[2]}$

1 Mix land uses

2 Take advantage of compact building design

3 Create a range of housing opportunities and choices

4 Create walkable neighborhoods

5 Foster distinctive, attractive communities with a strong sense of place

6 Preserve open space, farmland, natural beauty, and critical environmental areas

7 Strengthen and direct development towards existing communities

8 Provide a variety of transportation choices

9 Make development decisions predictable, fair, and cost effective

10 Encourage community and stakeholder collaboration in development decisions

According to the latest United Nations Population report, the North American region will be the highest proportion of the global population of the city by 2050 , where more than $70 \%$ people living in the city. ${ }^{[3]}$ with the enormous change of global urbanization course, we need to build a sustainable city with smart growth. With the help of the gray prediction model,we can learn about the changing trends in the city's future in order to achieve smart growth. 
Symbols and Definitions

Table 1 variable description

\begin{tabular}{cc}
\hline Abbreviation & Meaning \\
\hline EI & Economic Index \\
SEI & Social Equal Index \\
ESI & Environmental Sustainability Index \\
SGI & Smart Growth Index \\
\hline
\end{tabular}

\section{Gray Prediction Model}

Gray prediction model is a kind of forecasting method which is based on the information of small and incomplete original data. Due to the regularity of the change of the data, we can establish the corresponding differential equation model to predict the development trend. We select Darwin as a representative Oceania country over the past six years of data (including economic index, social equal index and environmental sustainability index, smart growth index) to predict in the future 15 years, and judge whether the city can achieve smart growth.

\subsection{Smart Growth Index Based on gray prediction}

We collect the value of 20 evaluation metrics on smart growth, respectively,including GDP, PPI, urban population and forest coverage, etc.

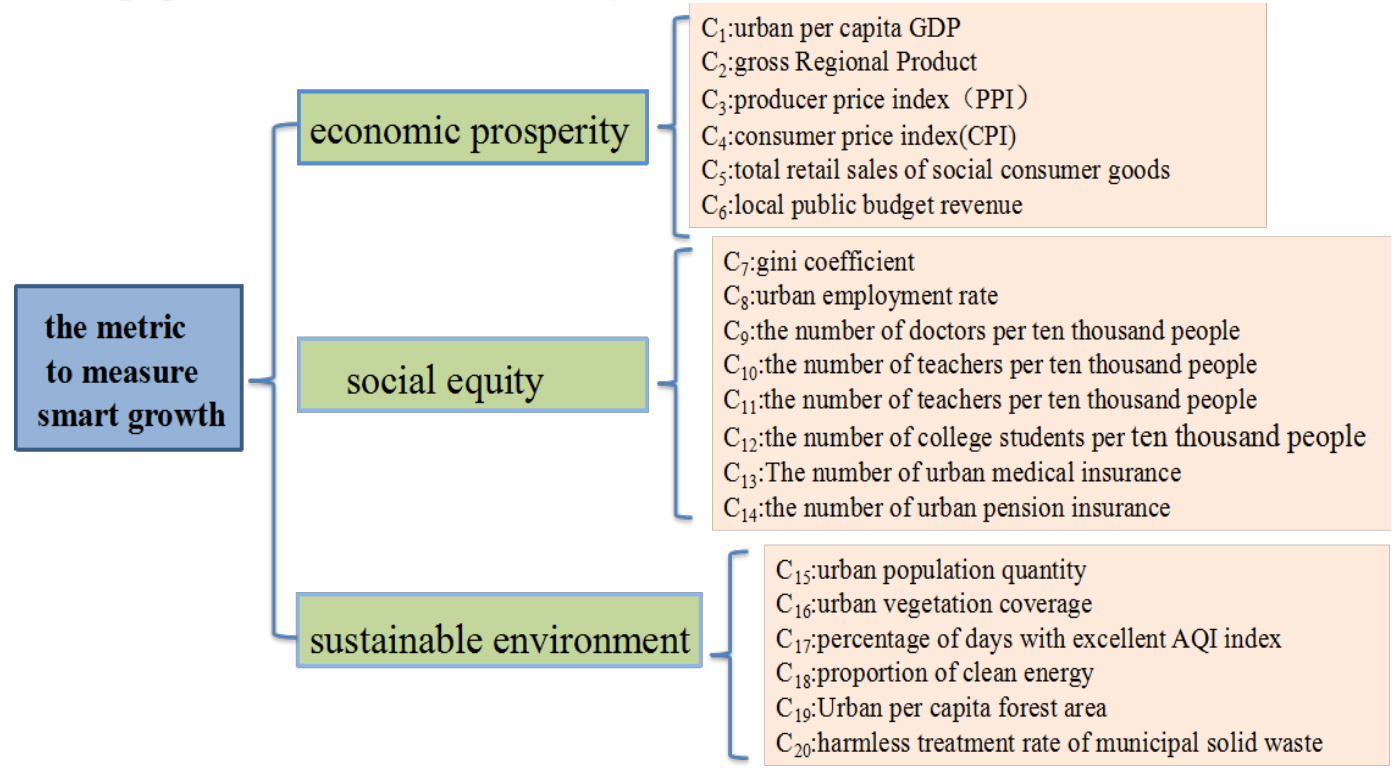

Figure 120 indicators on smart city growth

We multiplied the value and different weight respectively to get EI, SEI, ESI and SGI.The different weight depends on the subjective important proportion for smart cities. The following results are obtained.

Table 2 index value of Darwin

\begin{tabular}{c|c|c|c|c|c|c|}
\multicolumn{7}{|c|}{ Darwin } \\
\hline & 2010 & 2011 & 2012 & 2013 & 2014 & 2015 \\
\hline EI & 1223.02 & 1258.86 & 1272.08 & 1280.36 & 1323.83 & 1289.73 \\
\hline SEI & 63.00 & 64.40 & 67.47 & 69.22 & 71.96 & 73.22 \\
\hline ESI & 63.70 & 64.06 & 64.34 & 65.07 & 65.23 & 65.51 \\
\hline SGI & 1349.72 & 1387.32 & 1403.88 & 1414.64 & 1461.02 & 1428.46 \\
\hline
\end{tabular}




\subsection{The result of gray prediction}

Through the computer fitting,we get value and the curves.Darwin City's SGI showed a rising trend. the prediction error of curve is $10.56 \%$, which is reliable, and it can response to Darwin in future smart growth in a certain extent.At the same time,we can also get the future tendency of EI, SEI, ESI.

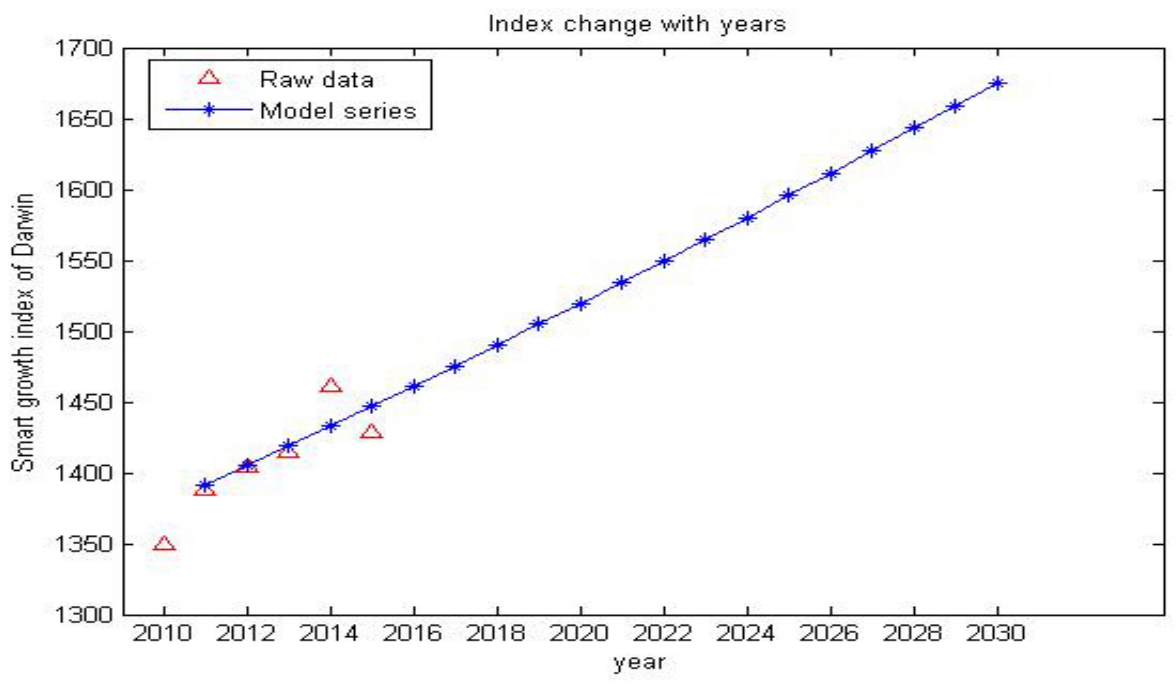

Figure 2 future tendency of SGI

According to the result of the gray prediction, we know in 2030 Darwin's SGI is 1675.57. In 2015, Darwin's $\boldsymbol{S G I}$ is 1428.46. Compared with the developed country (the average value of $\boldsymbol{S G I}$ is 1390 ), in 2015 only $102.77 \%$, and in 2030 reached $120.54 \%$. SGI is increased by $17.77 \%$.

According to the result of the gray prediction, we can predict in 2030 Darwin's $\boldsymbol{E I}$ will be 1491.97. In 2015, Darwin's EI is 1289.73, which increases 16.85\%. We can also predict in 2030 Darwin's $\boldsymbol{S E I}$ is 118.84. Meanwhile in 2015, Darwin $\boldsymbol{S E I}$ is 73.22, which increases 50.68\%. In 2015, Darwin's ESI is 65.51 . with the changing tendency, in $2030, \mathbf{E S I}$ will reach 71.59 , which increases $6.08 \%$.

\section{The Growth Plan Based on gray prediction}

From the data and curve trends,Darwin's smart growth is successful, but the overall index of success is not only the great success of economically prosperous index, but also socially equitable index and environmentally sustainable index. According to the data analysis, the current $\boldsymbol{S E I}$ in Darwin city is in the middle level. According to the gray prediction, Darwin will reach the average level of developed country' s SEI in 2022. It reflects the current scheme about $\boldsymbol{S E I}$ that has certain validity and rationality. However,the current Darwin environmental sustainability indicators are at an unsuccessful level. According to the current environmental sustainability plan, the city of Darwin in the past can not significantly improve this indicator. To sum up, the revision of smart growth plan should focus on social equity and environmental sustainability to increase $\boldsymbol{E S I}$ and $\boldsymbol{E I}$.

In order to make the value of $\boldsymbol{E S I}$ in Darwin reach an ideal value, we can make measures from the following aspects: firstly, educational administration can strengthen education, expand the teaching scale, reduce the tuition appropriately, reduce the dropout rate of city; secondly,government should strengthen the city public transportation construction to provide more convenient conditions for people to travel; last but no least,government should encourage people to medical career, further to improve the current health care system for the people's health and better escort. 
On the level of sustainable development of the environment to increase the value of $\boldsymbol{S E I}$, government authorities should further increase the coverage of vegetation and make rational use of land, instead of building more and buildings to attract tourists.

\section{Conclusions}

Through the gray prediction model, we can get a city smart growth related index changing trend and value. Grey prediction analysis, which do not need a large number of complete values to predict the future, however, it has high credibility. From the relevant values of sustainable city smart growth, we can know the advantages and disadvantages of urban intelligent growth, and propose the corresponding policies and measures proposed to improve the rate of change to achieve city smart growth.The gray prediction model is a good method.

\section{References}

[1]EPA, “This is Smart Growth.” 2016.

https://www.epa.gov/smartgrowth/smart-growth-publication Reference to a book:

[2] EPA, "Smart Growth: A Guide to Developing and Implementing Greenhouse Gas Reductions Programs.” 2011.

http://www.sustainablecitiesinstitute.org/Documents/SCI/Report_Guide/Guide_EPA_SmartGro wthGHGReduction_2011.pdf

[3] “In 2050 there will be 70\% people in the world.” 2008.

http://news.qq.com/a/20080228/002722.htm 